\title{
La construcción del canon y la cuestión del valor literario
}

\section{The Construction of Cannon and the Matter of Lierary Value}

\author{
Idelber Avelar \\ Tulane University \\ idelberavelar@gmail.com
}

Resumen - Este ensayo plantea la premisa de que en todo estudio literario está presente, de una u otra forma, la pregunta por el valor. Desde aquí, centrándose en la crítica y algunas problemáticas respecto a ésta, se desarrolla una breve panorámica sobre el tema del juicio y del "valor literario", partiendo por algunos preceptos del New Criticism, pasando, entre otros, por algunas reflexiones de Wayne Booth, hasta llegar, acercándose y poniendo en tensión su concepto de canon, a Harold Bloom.

Palabras clave: valor literario, canon, crítica.

Abstract - The following essay raises the premise that in every literary study there's the question of value, one way or another. From that point, and focusing in the criticism and some problems that are attached to it, it is developed a brief panoramic view on the subject of judgment and «literary value», beginning from some precepts found in New Criticism, and passing, among others, through some reflections of Wayne Booth until arriving to Harold Bloom, examining and tensioning his concept of Canon.

Keywords: literary value, canon, criticism.

La primera premisa de este ensayo está muy lejos de ser universalmente aceptada: no hay estudio de la literatura, por más descriptivo que sea, en el que una respuesta a la pregunta acerca del valor no esté, de alguna manera, presente. De allí que no todas las corrientes interpretativas acepten plantearla explícitamente, por cierto. De hecho, durante varias décadas del siglo XX, la regla fue negar la validez misma de la interrogante. Si tomamos la historia de la crítica en el mundo anglosajón, el New Criticism, dominante durante décadas, de inmediato viene a la mente como un intento de construir una empresa crítica desprovista de cualquier contenido axiológico. Northrop Frye, en Anatomía de la crítica, delimita el terreno al separar la crítica de la historia del gusto:

En la historia del gusto, donde no hay hechos, y donde todas las verdades han sido, de manera hegeliana, rotas en medias verdades. Sentimos quizás que el estudio de la literatura es demasiado relativo y subjectivo para jamás tener cualquier sentido consistente. Pero 
como la historia del gusto no tiene ningún vínculo orgánico con la crítica, ella puede ser fácilmente separada (1957: 18).

Un poco antes: «La historia del gusto no es una parte de la estructura de la crítica, así como el debate Huxley-Wilberforce no es una parte de la estructura de la ciencia biológica» (18). Lo curioso de la analogía de Frye, por cierto, es que no está para nada claro que la polémica Huxley-Wilberforce no sea parte de la estructura de la biología, así como no está para nada claro que la polémica Marx-Ricardo no sea parte de la estructura de la ciencia económica. En la medida en que se recorren las páginas de Anatomía de la crítica, se va imponiendo una conclusión: siempre que se diga que la crítica es «fácilmente separable» del gusto (del juicio, del valor), uno puede estar razonablemente seguro de que dicha separación es lo «menos fácil» que hay.

El lector de Frye se da cuenta de ello cuando llega al espinoso momento en que el autor tiene que justificar sus elecciones y echa mano de una curiosa tesis, la de que es preferible que los valores que subyacen a las elecciones estéticas queden silenciosamente escondidos:

Las estimativas comparativas de valor son realmente inferencias, más válidas cuando silenciosas, de la práctica crítica, no principios expresados que guían su práctica. El crítico verá pronto, y constantemente, que Milton es un poeta más sugestivo y de más recompensa que Blackmore. Pero cuanto más obvio se vuelve esto, menos tiempo él querrá insistir en el punto. Porque insistir en ello es todo lo que puede hacer: cualquier crítica motivada por un deseo de establecerlo o probarlo será meramente un documento en la historia del gusto (Frye, 1957: 25).

Es espantoso, pero esto es lo que nos sugiere Anatomía de la crítica: 1) la crítica es una esfera separada de la historia del gusto; 2 ) es "obvio» que algunos poetas son mejores que otros; 3) cualquier intento de explicar por qué esto es así será parte de la historia del gusto, no de la crítica; 4) por lo tanto, es mejor dejar el fundamento de las elecciones estéticas sin discusión, porque si no las cosas se complican demasiado. Qué se subraye: no estamos creando aquí un espantajo artificial, es decir, no tomamos un borrador mal compuesto por algún académico. Anatomía de la crítica es uno de los libros de crítica literaria más influyentes del siglo XX. Se sostiene, sin embargo, sobre un trípode de premisas de visible precariedad: 1) la crítica y el valor no se mezclan, ya que éste es una mera parte de la historia del gusto; 2) no se hace crítica sin una elección valorativa implícita; 3) como ya hemos definido la valoración como parte de una historia del gusto externa a la crítica, aun reconociendo que la actividad crítica depende de una elección valorativa, escondamos debajo del carpete los criterios que subyacen a ésta, a riesgo de que se nos desmorone todo el edificio armado.

Se podría demostrar que la aporía que detectamos en el New Criticism se repite en todos los métodos interpretativos que intentaron hacer de la crítica literaria una operación descriptiva en la cual no tendría lugar el debate acerca de las opciones valorativas. Habrá que escribirse un día la historia de los métodos formales en el siglo XX, con especial atención a cómo el deseo de cientificidad entró en choque con lo que podríamos llamar la inevitabilidad valorativa. En el caso del formalismo ruso, estos dos ejes coexistieron no sin tensión. El anhelo de crear un lenguaje científico para la descripción de las operaciones del lenguaje poético los lleva a definir lo propio a la literatura a partir de la noción de extrañamiento (ostraneniye), entendida como prolongamiento de la percepción, debido a 
la dificultad y la novedad de las operaciones textuales sobre el lenguaje. En el momento más fructífero del desarrollo de las investigaciones de los formalistas, la consolidación del poder en manos de Stalin fuerza, de manera progresiva, a los formalistas al exilio o al silencio, no sin que antes Yuri Tynyanov formule algunas pistas de lo que podría haber sido una concepción formalista de la historia literaria. Para Tynianov, la literatura evolucionaría a través de la "parodia», es decir, el extrañamiento impuesto a las formas literarias congeladas, automatizadas por el uso excesivo. Siempre que un procedimiento formal pasara a ser parte del repertorio de prácticas ya esperadas, emergería una operación paródica que la extrañaría, haciendo visible la automatización anterior. Uno de los ejemplos clásicos, naturalmente, es lo que Don Quijote le hizo a las novelas de caballería. La sofisticación del aparato teórico llevaba a dos formalistas rusos, poco a poco, desde un inmanentismo textual a una teoría de la historia literaria, interrumpida brutalmente por la consolidación del poder burocrático en Unión Soviética.

Las restricciones hechas arriba al New Criticism norteamericano no se aplican a los formalistas rusos, en la medida en que ellos jamás excluyeron el tema del valor de la esfera de la crítica. Pero tampoco se dedicaron a tematizarlo explícitamente, aunque algunas de sus formulaciones presupongan una axiología. La insistencia en una función «descriptiva» de la crítica literaria, así como el énfasis en la condenación a los juicios de valor impresionistas y ligeros del simbolismo contra el cual se insurgían, demuestran que el formalismo ruso mantuvo una relación tensa y problemática con la inevitabilidad valorativa. Si se define el extrañamiento como lo más propio a la literatura y si se insiste en que la historia literaria evoluciona por la operación paródica sobre el congelamiento anterior de las formas, me parece inescapable la conclusión de que el valor recaería sobre las prácticas que más realiza este programa. En otras palabras, el edificio teórico de los formalistas nos lleva a la conclusión ineludible de que Don Quijote tiene un valor que no posee el Amadís de Gaula y que las vanguardias realizan el lenguaje literario de una manera que no lo hacen los parnasianos. Las conocidas conversaciones y afinidades entre el formalismo y el futurismo rusos prestan credibilidad a esta tesis. No hay nada de condenable en ello, por supuesto. Pero lo arrollamos como prueba adicional de que aun en las operaciones más formales, descriptivas y "científicas» de la crítica, la inevitabilidad axiológica se impone. Simplemente señalaremos que la misma inevitabilidad podría ser demostrada con respecto a la otra gran corriente formal de la crítica literaria del siglo $\mathrm{XX}$ - el estruturalismo- y veremos cómo ella se manifiesta en las corrientes críticas no caracterizadas por el anhelo de cientificidad, sino por la pulsión ética. Pasamos, entonces, al otro extremo: del descriptivismo formal, que supuestamente eludiría la valoración, a las corrientes que explícitamente reivindican la valoración ética como elemento constituyente de la actividad crítico-literaria.

The Company We Keep: An Ethics of Fiction, de Wayne Booth, ocupa un papel central en lo que se ha llamado la resurgencia de la crítica ética. Booth mantiene las premisas aparentemente contradictorias de que la crítica ética ha caído en desuso — «ella pasa sin mención en la mayoría de las discusiones entre críticos profesionales» (1988: 25) - y que «casi todos en nuestra escena son críticos 〈éticos» (67). La aparente contradicción se explica con el hecho de que, para Booth, cualquier posición estética o epistemológica siempre incluirá, aunque implícitamente, elecciones éticas. La crítica de Booth a la separación kantiana entre la filosofía moral y la filosofía estética, trae un eco de Hegel, quien ya señalaba que un «debe ser» se anunciaba bajo cada «es», en las definiciones kantianas 
de lo bello y lo sublime. Lo que lamenta Booth es la ausencia de una aclaración de los valores que subyacen aun a los análisis estéticos más especializados. En su intento de llenar este vacío, Booth abraza el proyecto humanista de ilustración a través de las letras, una «Conversación que Celebra las Muchas Maneras en que las Narrativas Pueden Ser Buenas Para $\mathrm{Ti}$ - con Vislumbres de Cómo Evitar Sus Poderes para el Mal» (ix), como lo define en la introducción. Tomando distancia del prescriptivismo de la filosofía moral, Booth muestra cómo la reflexión sobre el encuentro entre el ethos de un texto o del autor implícito con el del lector, no se deja subsumir bajo un mero conjunto de normas. "Posponiendo la mayoría de las preguntas acerca la buena o la mala moral, en su sentido ordinario", Booth subraya el hecho de que "las distinciones éticas no dependen de la elección entre valores ‘morales» tradicionales» (179). Consciente de que las condenas moralizantes de una tradición que va de Platón a Leavis «le dieron a la crítica ética una mala fama", Booth propone la pregunta: "¿Podremos esperar encontrar una crítica que respete la variedad y ofrezca un saber acerca de por qué algunas ficciones valen [are worth] más que otras?» (36).

Cualquier intento de sostener esta última premisa - la de que algunas ficciones realmente valen más que otras- sólo podría dispensar con una moral implícita al recurrir a una investigación acerca de los procesos históricos a través de los cuales ciertos valores «han sido asignados» a aquellas ficciones. Si no, es decir, si seguimos tomando tales valores como intrínsecos - ya sea "potencialmente» o «realmente» presentes, como intenta distinguir Booth cuando tropieza en el problema (89)— jamás podríamos «respetar la variedad», o no estaríamos llevando nuestra posición a su conclusión lógica necesaria, es decir, la advocación de aquellos valores sobre otros, que valdrían «menos» que los primeros. Los que han manejado el admirable tratado de Booth han notado un diálogo subterráneo con la teoría contemporánea, pocas veces explícito en el libro, como en la reevaluación de Rabelais a la luz del feminismo (383-418). El reto que se le presenta es mantener algunas de las premisas de la teoría contemporánea (acerca, por ejemplo, de la variabilidad histórica del sentido o de la imposibilidad de una medida trascedental de valor) a la vez que se agarra a la noción de la literatura como proveedor singular de una "sumersión en otras mentes» (142). Company es, entonces, un minucioso intento de definir en qué consistiría este «Bien» y este «Mal», en un esfuerzo por aceptar la variabilidad de interpretaciones (que Booth defiende en nombre del "pluralismo») mientras, a la vez, se rehúsa a desplazar la discusión del terreno del valor intrínseco al terreno de la valoración social. Booth realiza esta difícil tarea a través de una serie de ejercicios en reductio ad absurdum, como el contraste entre King Lear y un ejemplar de la revista pornográfica Hustler, o aún entre un poema de Yeats y una broma improvisada en verso. Después de superar moralmente tales fantasmas imaginarios, la gran literatura reemergería intacta, con su insustituible función moral reasegurada.

Se trata, en Booth, de un modelo pedagógico: lo ético se piensa como el «efecto» ejercido por el texto. Este modelo contrasta con la tendencia antihumanista de la crítica contemporánea, que concibe la literatura como una construcción lingüística, cultural e histórica, cuyo valor sólo puede determinarse a través de una perspectiva más agnóstica y distanciada. La necesidad de caminar sobre la cuerda floja que separa el reconocimiento de las contingencias formales e históricas y el compromiso humanista, lleva a Booth a machacar incesantemente la conocida cantilena: lo que es bueno acá no es bueno allá, esto puede ser bueno para ti, pero no para mí, cualquier virtud llevada al extremo puede 
destruir las demás, una dosis excesiva de cualquier valor (ya sea la ironía, la apertura formal, o cualquier otro) puede ser perjudicial en vez de positiva etc. (49-79). Booth trata de encontrar el área gris que permitiría al crítico sensible evitar el «silogismo universal» (esta obra es buena porque posee X; por lo tanto, todas las obras que posean X...) sin renunciar a la premisa de un valor ético intrínseco a la literatura y a algunas obras literarias más que a otras. El objetivo es evitar los «riesgos» de demasiada «clausura» y de demasiada «apertura». Los tropiezos de la crítica ética serían explicables por su tentación especial de «sobregeneralizar» (51). Se trata, entonces, de un pluralismo moderado que mantiene la equivalencia entre lo ético y una concepción inmanentista de valor según la cual éste, no importa cuán variable, siempre trascendería, existiría independiente de cualquier valoración social.

Siempre que se remite un problema a la «tentación de sobregeneralizar», el terreno está preparado para que el liberal sensible busque la reconciliación razonable. Al contrario de lo que sugieren los argumentos de Booth (350), no estamos ante un pluralismo radical, sino liberal. Al hablar de la crítica contemporánea Booth afirma que «el énfasis en la variedad de interpretaciones nos dice poco acerca del valor real de las obras» $(84),{ }^{1}$ afirmación que sólo tiene sentido si uno se aferra a la noción de que las obras poseen un valor como una suerte de propiedad inherente o esencia eterna, es decir, si uno se rehúsa a considerar en forma seria el argumento de que todo valor es producto de una operación socialmente contingente e históricamente variable - posición que Booth descarta como «subjetivista» (73). Los ataques al «subjetivismo»y al «relativismo» desde el punto de vista de una ética humanista son bien conocidos y Booth los repite ad nauseam: "se presupone claramente una completa equivalencia en la competencia de todos los intérpretes en el argumento de que las obras no poseen o ejercen valor inherente, sino que solamente son valoradas» (85). He ahí otra versión de lo que Barbara Herrnstein Smith ha denominado la falacia egalitaria, o sea, «la recurrente ansiedad / acusación / reclamo de que, a menos que un juicio se pueda demostrar como más ‘válido〉 que otro, todos los juicios deben ser <iguales〉 o <igualmente válidos»» (1998: 98). La falacia egalitaria se sostiene a través de una fantasía anclada en una suerte de Robinson Crusoe crítico: «me parece más difícil creer que si una persona de nuestra cultura que es completamente inexperiente, no ve absolutamente ningún valor en, digamos, las novelas de Faulkner, sus opiniones sean tan pertinentes a nuestro discurso sobre Faulkner como las opiniones de lectores experientes» (85). La falacia es que, obviamente, una "persona» inexperiente en literatura no podría pertenecer a la misma «nuestra cultura» que «los lectores experientes»; sus opiniones, por definición, no serían igualmente pertinentes a "nuestro» discurso (siempre hay que preguntarse, la deconstrucción y el marxismo nos han enseñado, cuál instancia de enunciación se esconde detrás de un pronombre de primera persona plural). En realidad, es "precisamente porque» los valores emergen como articulaciones de interacciones y conflictos sociales que podemos concluir que no todos los juicios son iguales ni igualmente válidos. Exactamente porque las valoraciones no son ni igualmente válidas ni epistémicamente iguales en sus posiciones respecto a las relaciones de poder, que ellas

En realidad, una mirada a algunas de las tendencias dominantes de la crítica contemporánea demostraría que la emergencia de muchas de las cuestiones éticas reconocidas por Booth - es decir, aquellas que atañen a la raza, la clase y el género- ha dependido de, y dialogado con, la "disección formalista» de «textos", que Booth descalifica como ideológicamente neutra (422). Para comprobar el equívoco de Booth, basta pensar en Shklovski, Brecht, Benjamin, Beauvoir, Butler, Lamming o Henry L. Gates, para ser lo más ecléctico posible en el contraejemplo. 
jamás son intercambiables. Uno u otro nunca es materia de indiferencia, por más que la ansiedad esencialista nos trate de convencer que si la valoración se ha desplazado de una inmanencia durmiente a una red de relaciones sociales, todos los valores se han vuelto, de alguna forma, idénticos a todos los demás. ${ }^{2}$

Si los inmanentismos formales no escapan de la axiología, por más que se quieran descriptivos y científicos, la crítica humanista, que en ningún momento intenta esconder su compromiso con la noción de que la literatura «debe» defender determinados valores éticos, padece de la imposibilidad de fundamentarlos más allá de la tautología. Por cierto, la crítica prescriptiva ha arrollado una infindable lista de fundamentos trascendentales a partir de los cuales se debería juzgar la literatura: la formación del carácter, la renovación del lenguaje, el progreso del espíritu humano, la emancipación del proletariado. Ninguno de estos fundamentos se sostiene, sin embargo, como base para una estética sin la remisión a otro valor que lo justificaría. La pregunta: «¿por qué debe ser ésa la función de la literatura?» no puede ser respondida inmanentemente. Ella inevitablemente disparará un proceso de regresión infinita. La fundamentación del valor en la estética tendría, así, una estructura necesariamente abismal. La teórica norteamericana Barbara Herrnstein Smith —quien es la que puso algún orden en esta discusión, me parece- resumió el asunto con un axioma: el valor es siempre y necesariamente «contingente» (1988: 30-53).

"Contingente» no quiere decir «subjectivo» ni «relativo» ni «arbitrario». Un determinado valor puede perfectamente ser "objectivo" (en la medida en que independería de la subjectividad particular de cualquier miembro de la comunidad), «absoluto» (puesto que no relativizable dentro de dicha comunidad) y "motivado" (en el sentido de que su origen no sería producto de una elección puramente arbitraria). Nada de esto cambiaría su naturaleza esencialmente contingente. La expresión clave aquí es, por supuesto, «dentro de la comunidad». Un valor es siempre el resultado de una pugna entre grupos sociales cuyo resultado no está dado de antemano. Se podría argumentar que cuánto más exitoso es el pacto que se sigue al resultado de la pugna, «más ese valor contingente aparecerá a los miembros de la comunidad como una no contingencia». Los ejemplos son legión. Bastaría pensar en el considerable poder de tracción de valores como el "mester de clerecía» (la técnica aprendida en la tradición) para la literatura tardomedieval, la adecuación a los modelos grecoromanos para la literatura neoclásica del siglo XVIII o la innovación y la ruptura para las vanguardias de principios del siglo XX. En cada uno de estos casos, la justificación de un valor históricamente contingente hizo uso de un vocabulario de la no contingencia, es decir, operó, en alguna medida, una trascendentalización de un proceso que era estrictamente inmanente a la comunidad valorativa en cuestión.

La posición agnóstica adoptada aquí es la de que el grado de estabilidad de estos valores entre sus sendas comunidades no nos dice nada sobre su supuesta obviedad o necesidad, sino que expresa el proceso de naturalización del resultado de un pacto valorativo.

\footnotetext{
Pese a los mejores esfuerzos para evitar las descalificaciones moralistas, la ansiedad acerca del valor lleva a Booth a considerar los productos de la cultura de masas "como Jaws» como objetos que «se acercan al límite de lo sin valor» (206). El problema se vuelve claro cuando uno compara este comentario con la reconstrucción intrincada hecha por Fredric Jameson, de las alegorías de la novela y de la película y sus sendas representaciones de un cierto patrón de conflictos de clases mascarados en los EEUU post derechos civiles, los roles ideológicos tanto del sistema policial como de la retórica cientista en el film, su contenido utópico velado, etc. («Reification», 26-30). En este caso, claramente, el moralismo estético ha impedido al crítico, a Booth, ver y enfrentarse con una rica textura de problemas políticos y culturales presentes en la película.
} 
Tomemos, por un momento, un ejemplo latinoamericano: ya es ampliamente hegemónica la percepción de que, sea cual fuere la crítica que uno pueda tener a la estética del realismo mágico, su versión original con Cien años de soledad, de Gabriel García Márquez, disfruta de una legitimidad no conferida a la versión epigonal que se encuentra en, digamos, La casa de los espíritus, de Isabel Allende. Desde luego, es posible cuestionar esa valoración, pero no sin instalarse en posición considerablemente exterior al consenso crítico que preside las comunidades interpretativas en las cuales circulan estos textos. El éxito del cuestionamiento dependerá, por lo tanto, de la capacidad del analista de develar la naturaleza «contingente» de la aparente naturalidad de la valoración anterior. Esta posición, de agnosticismo axiológico, es frecuentemente confundida con el relativismo puro y simple, que afirmaría que «todos los valores son igualmente válidos» o, para recurrir a una expresión popular, que "da todo lo mismo». Nietzsche, al cuestionar la supuesta obviedad de valores como «el bien», «la piedad», «la humildad» y «la generosidad", nos enseñó algo acerca de cómo funcionan las operaciones de desnaturalización. La acusación de relativismo se repite cuando, al interior de una comunidad, se cuestiona un valor presuntamente absoluto. Para los que experiencian una contingencia como si ésta fuera una no contingencia, cualquier alteración del orden provocará la sensación de que ningún orden es posible. Las reacciones preocupadas al agnosticismo axiológico que encontramos, por ejemplo, en la crítica ética de Wayne Booth, se repiten, mutatis mutandi, en la reacción de la crítica estética de, por ejemplo, un Harold Bloom, en su El canon occidental (1994).

Para Bloom, feministas, marxistas, deconstruccionistas, lacanianos, neohistoricistas y afrocéntricos serían los agentes contemporáneos de una «Escuela del Resentimiento» que «niega a Shakespeare su palpable supremacía estética» (1994: 20) y proclama «la apertura del Canon» con la incorporación de obras que «no deben y no pueden ser releídas, porque su contribución al progreso social es su generosidad de oferecerse para rápida ingestión y desecho» (30). Irónicamente, a un crítico que responsabiliza la Escuela del Resentimiento por el hecho de que "como crítico literario, [vivo] en lo que considero la peor de todas las épocas para la crítica literaria» (22), se le puede reprochar cualquier cosa, excepto no haber hecho bastante visible su propio resentimiento. El paralelismo que establecemos entre la crítica ética de Booth y la crítica estética de Bloom, en realidad, no le hace completa justicia a aquél, ya que en Booth encontramos por lo menos algún intento de leer al interlocutor. A frases como «el radicalismo académico llega al punto de sugerir que las obras se incorporan al Canon a causa de exitosas propagandas [advertising] y campañas de indoctrinación [propaganda]» (Booth: 20), no hay respuesta posible si no preguntar: "¿quién jamás ha dicho esto?». En obras que se dedicaron a revisar el canon desde una perspectiva feminista, como The Madwoman in the Attic, de Sandra Gilbert y Susan Gubar, o desde una perspectiva afro, como The Signifying Monkey, de Henry Louis Gates, Jr., seguramente no encontramos cualquier ecuación entre la construcción del canon y la operación de una propaganda. Si es cierto que buena parte de la crítica contemporánea se ha dedicado a estudiar el proceso de emergencia de los cánones -y aquí se sugiere la obra indispensable de John Guillory, Cultural Capital-, sería difícil encontrar un solo estudio serio que defendiera algo que aun vagamente recordara la caricatura de Bloom. Sobre frases como "no estoy preparado para coincidir con los marxistas en que el Canon Occidental sea otra instancia de lo que ellos llaman «capital cultural»» (Booth: 37), resulta inevitable observar que ella no pasaría en un examen de 
sociología elemental. Como bien sabe cualquier buen estudiante de pregrado de ciencias humanas, el concepto de "capital cultural» viene de Pierre Bourdieu, un sociólogo francés con muy pocas relaciones con la tradición marxista. Más que atacar a Bloom, se trata aquí de señalar una graciosa paradoja. Si Bloom insiste con tanto énfasis en afirmar que "Shakespeare inventó a todos nosotros» (1998: 40) — y es ubicua su reiteración de que Shakespeare es el padre de «todos»-, es imposible no preguntarse qué padre es ése que, aunque perfecto, produce hijos tan bárbaros y deleznables como estos afrocéntricos y estas feministas. De Bloom, me siento tentado a extraer otro axioma: cuánto más amenazado se sientan los guardianes de la presunta universalidad de un determinado valor, cuánto más socialmente precario sea su fundamento, menor será su capacidad de entrar en genuino debate con la fuerza emergente, con la irrupción crítica que viene de afuera para señalar el carácter contingente de dicho valor.

Entiendo que el lector pueda estar ansioso por el momento propositivo, programático, positivo de este ensayo. Si mantengo 1) que todos los valores estéticos son productos de una pugna entre grupos sociales que termina consolidando una contingencia y, en el proceso, creando las condiciones para que ella se presente como una no contingencia; y 2) que esto no supone cualquier tipo de posición «universalmente relativista» (valga el oxímoron), es decir, que de allí no se deduce que el valor que se imponga a cada momento sea indiferente, sin duda es legítimo preguntar: "¿qué concepción de valor estético defiendes entonces?». Por razones análogas a las de Marx, quien se rehusaba a describir la sociedad comunista futura e insistía en la crítica radical a la realidad efectivamente existente, sigo apostando a un desmontaje escéptico de la presunta universalidad de los fundamentos de la estética heredada de la tradición occidental —ante la cual, desde luego, no hay exterioridad posible ni deseable. La circulación y el prestigio de diatribas como las de Harold Bloom me convencen de que esta tarea apenas ha comenzado.

Resignarse a una posición para la cual lo único verdaderamente universal es la necesidad del martillo de la razón crítica, no impide intervenciones programáticas locales en los debates axiológicos. En cuanto al canon latinoamericano, por ejemplo, he insistido en una valoración incisiva de escritos más perturbadores y menos triunfalistas como los de Juan Carlos Onetti o José María Arguedas, por oposición a las obras más identitarias y, en cierta medida, más reconfortantes de un García Márquez, de un Vargas Llosa o de un Carlos Fuentes, novelistas incomparablemente más valorados por la tradición crítica heredada del boom (Avelar, 2000: 18-29). Lo que sí sigo resistiendo es la universalización de esta intervención local como modelo axiológico definitivo, en un momento en que - de nuevo como ejemplo- una cierta melancolía onettiana adquiere contornos de Zeitgeist dominante en algunas sociedades postdictatoriales, convirtiendo la parálisis politica en una etiqueta elegante e inofensiva. Adentrando en un terreno mucho menos conocido para mí, creo que sería productivo investigar - a lo mejor alguien ya lo ha hecho- cuáles han sido las pautas, los criterios, las premisas y los valores subyacentes a la notable canonización de ciertas obras de la «estética de la neoviolencia», como La virgen de los sicarios, de Fernando Vallejo, en la literatura colombiana contemporánea. La interrogante se me ocurre porque he acompañado y participado - aquí sí mucho más de cerca- en la revisión y el cuestionamiento de la canonización de obras análogas en la tradición brasileña, como Cidade de Deus, de Paulo Lins. Resguardándose las diferencias entre las sociedades brasileña y colombiana, y entre las dos obras citadas, no creo que la comparación sea improcedente. Un cierto registro hiperrealista de representación de la 
violencia ha sido incorporado al canon como una voz «desde adentro» de comunidades que no habían, con frecuencia, accedido a la representación literaria. Esta instalación de la interioridad respecto a determinado grupo social como criterio valorativo en la estética merece, creo, ser interrogada de manera incisiva.

Reconozco que el momento programático de la posición que se defiende aquí es bastante modesto y localista. Estoy convencido de que, a la larga, esta "táctica de guerrilla» en el acercamiento al canon puede producir efectos más duraderos que cualquier postulación acerca de cuál debería ser el nuevo valor literario universal. Hay algo de anticlimáctico en esta elección, por cierto. Este ensayo no está lejos de argumentar que el más absoluto valor estético debe ser aquél que nos permita, a cada momento, desarmar completamente los absolutos y volver a rearmarlos, permitiéndonos vislumbrar algo obnubilado en los arreglos anteriores. Lo que quizás no sea, al fin y al cabo, un programa tan modesto para la literatura, en una época en que la doxa política y periodística reinstala la creencia en universales cuyos compromisos y complicidades particulares quedan, tan a menudo, más que visibles.

\section{REFERENCIAS}

Avelar, Idelber. (2000). Alegorías de la derrota: La ficción posdictatorial y en trabajo del duelo. Santiago: Cuarto Propio.

Bloom, Harold. (1994). The Western Canon: The Books and School of the Ages. Nueva York, San Diego y Londres: Harcourt Brace.

Booth, Wayne. (1998). The Company We Keep: An Ethics of Fiction. Berkeley y Los Angeles: University of California P.

Frye, Northrop. (1957). Anatomy of Criticism: Four Essays. Princeton: Princeton UP.

Gates, Jr., Henry Louis. (1988). The Signifying Monkey: A Theory of Afro-American Literary Criticism. Nueva York: Oxford UP.

Gilbert, Sandra y Susan Gubar. (1979). The Madwoman in the Attic: The Woman Writer and the Nineteenth-Century Literary Imagination. New Haven: Yale UP.

Guillory, John. (1993). Cultural Capital: The Problem of Literary Canon Formation. Chicago: University of Chicago P.

Herrnstein Smith, Barbara. (1998). Contingencies of Value: Alternative Perspectives for Critical Theory. Cambridge, Mass y Londres.

Recepción: septiembre de 2009

Aceptación: octubre de 2009 